10. Medrano C, Vergez F, Mengelle C, Faguer S, Kamar N, Del Bello A. Effectiveness of immune checkpoint inhibitors in transplant recipients with progressive multifocal leukoencephalopathy. Emerg Infect Dis. 2019;25:2145-7. https://doi.org/10.3201/eid2511.190705

Address for correspondence: Nicolas Lambert, Service de Neurologie, CHU de Liège, Avenue de l'Hopital, 1, 4000, Liège, Belgium; email: nicolas.lambert@chuliege.be

\section{Unexpectedly High Prevalence of Hepatitis C Virus Infection, Southern Laos}

\author{
Antony P. Black, ${ }^{1}$ Vilaysone Khounvisith, ${ }^{1}$ \\ Kinnaly Xaydalasouk, ${ }^{1}$ Kong Sayasinh, \\ Aurelie Sausy, Claude P. Muller, Judith M. Hübschen \\ Author affiliations: Institut Pasteur du Laos, Vientiane, Laos \\ (A.P. Black, V. Khounvisith, K. Xaydalasouk); Saravan Provincial \\ Hospital, Saravan, Laos (K. Sayasinh); Luxembourg Institute of \\ Health, Esch-sur-Alzette, Luxembourg (A. Sausy, C.P. Muller, \\ J.M. Hübschen)
}

DOI: https://doi.org/10.3201/eid2801.211307

During 2017-2019, a total of 88/753 (11.7\%) of patients 5-90 years of age in hospitals in Saravan Province, Laos, were seropositive for hepatitis $C$ virus antibodies. Viral RNA was found in 44 samples. Sequencing showed high diversity within genotype 6 . We recommend exposurerisk investigations and targeted testing and treatment.

Tepatitis $\mathrm{C}$ virus (HCV) infection carries high risk Ifor progression to chronic status and liver complications, such as cirrhosis and cancer. Transmission usually occurs through blood (e.g., during medical procedures, blood transfusions, tattooing, or intravenous drug use). Because those who clear the virus remain HCV antibody positive, testing for viral RNA is essential for diagnosis of chronic infection (1).

We conducted a cross-sectional, hospital-based study during May 2017-March 2019 to determine seroprevalence and genotyping of HCV in Saravan Province

${ }^{1}$ These authors contributed equally to this manuscript. in southern Laos. Saravan Province has a population of $\approx 400,000$ distributed over 8 districts, 2 bordering Vietnam to the east and 2 bordering Thailand to the west. In 2017 , only $8.5 \%$ of men and $6.9 \%$ of women had health insurance; $36.8 \%$ of the provincial population was in the poorest wealth index quartile; $17.8 \%$ of households had no electricity; and only $54.3 \%$ of men and $44.7 \%$ of women were literate, the lowest literacy rates in Laos (2).

We nonrandomly selected 753 participants from a larger study (Appendix, https://wwwnc.cdc.gov/ EID/article/28/1/21-1307-App1.pdf) (3); participants were persons $>5$ years of age who were recruited for the larger study while seeking care at the provincial hospital or 1 of 3 district hospitals. Overall, 11.7\% (88) participants were $\mathrm{HCV}$ antibody seropositive, compared with $<2 \%$ in previous studies in Laos $(4,5)$ (Figure; Appendix). Only 2 seropositive patients were at the hospital for hepatitis-related reasons; HCV seroprevalence was not significantly different regardless of whether or not participants sought care for reasons associated with hepatitis. After multivariate analysis, those $>30$ years of age had much higher seroprevalence $(70 / 350$, $20 \%)$ than those $\leq 30$ years of age $(18 / 403,4.5 \%$; odds ratio [OR] 4.2; $\mathrm{p}<0.001)$. This higher seroprevalence indicates either that older adults are at higher risk for exposure or that the older adults were infected some time ago, during childhood or early adulthood. Participants who practice Animism had a slightly higher seroprevalence $(81 / 495 ; 16.4 \%)$ than followers of Buddhism or other faiths $(7 / 258,2.7 \%$; OR 3.0; $p=0.02)$, and married participants had slightly higher seroprevalence $(81 / 485,16.7 \%)$ than single participants $(7 / 268,2.6 \%$; OR 2.7; $p=0.04)$, although the associated risk factors are unknown (Table; Appendix).

Whether the observed west-east increase in seroprevalence is related to the proximity of Samuoi district $(24.4 \%$ anti-HCV seropositive) to the Vietnam border remains unclear (Figure; Appendix). Although HCV seroprevalence in Quang Tri, a bordering province in Vietnam, has been reported to be $<1 \%$ (6), much higher rates were found in different groups at high risk in Vietnam, such as intravenous drug users (IDU) and men who have sex with men (MSM) (7). We could find no reported link between the Samuoi district population and the IDU or MSM communities in Vietnam, although this link remains possible.

Seroprevalence was significantly higher among the Pako ethnic group $(66 / 265,24.9 \%$ vs. $22 / 488$, $4.5 \%$; OR 5.1; $\mathrm{p}<0.001)$, which makes up most of the population in Samuoi district but not elsewhere. The Pako practice nonsterile teeth filing and lacquering during early adolescence with shared equipment and associated bleeding, although this practice is 
in decline. Pako do not often practice tattooing, but the women have ear piercings, which could be another source of infection. Other risk factors, such as blood transfusions and practices of MSM and IDU, are thought to be rare in this population, but nonsterile injection of traditional medicine might occur (8; A. Sernsarae, Samuoi District Health Office, pers. comm., 2020 Jul 23).

Only 44 of the samples we tested were positive for HCV RNA. The relatively low rate of chronic in- fection could indicate exposure early in life; persons infected at $<25$ years of age are thought to have much lower risk for chronic infection (1). A substantial proportion of children in our study were also infected, either by mother-to-child transmission or through the same routes as the adults in the study.

We obtained sequence data for 39 samples. All belonged to genotype 6 (Appendix). The sequence diversity does not suggest any recent large-scale transmission events, because no identical sequences

Figure. HCV seroprevalence, Laos, May 2017-March 2019. A) Location of Saravan Province; B) districts of Saravan Province. Colors represent seroprevalence levels. HCV, hepatitis $\mathrm{C}$ virus.

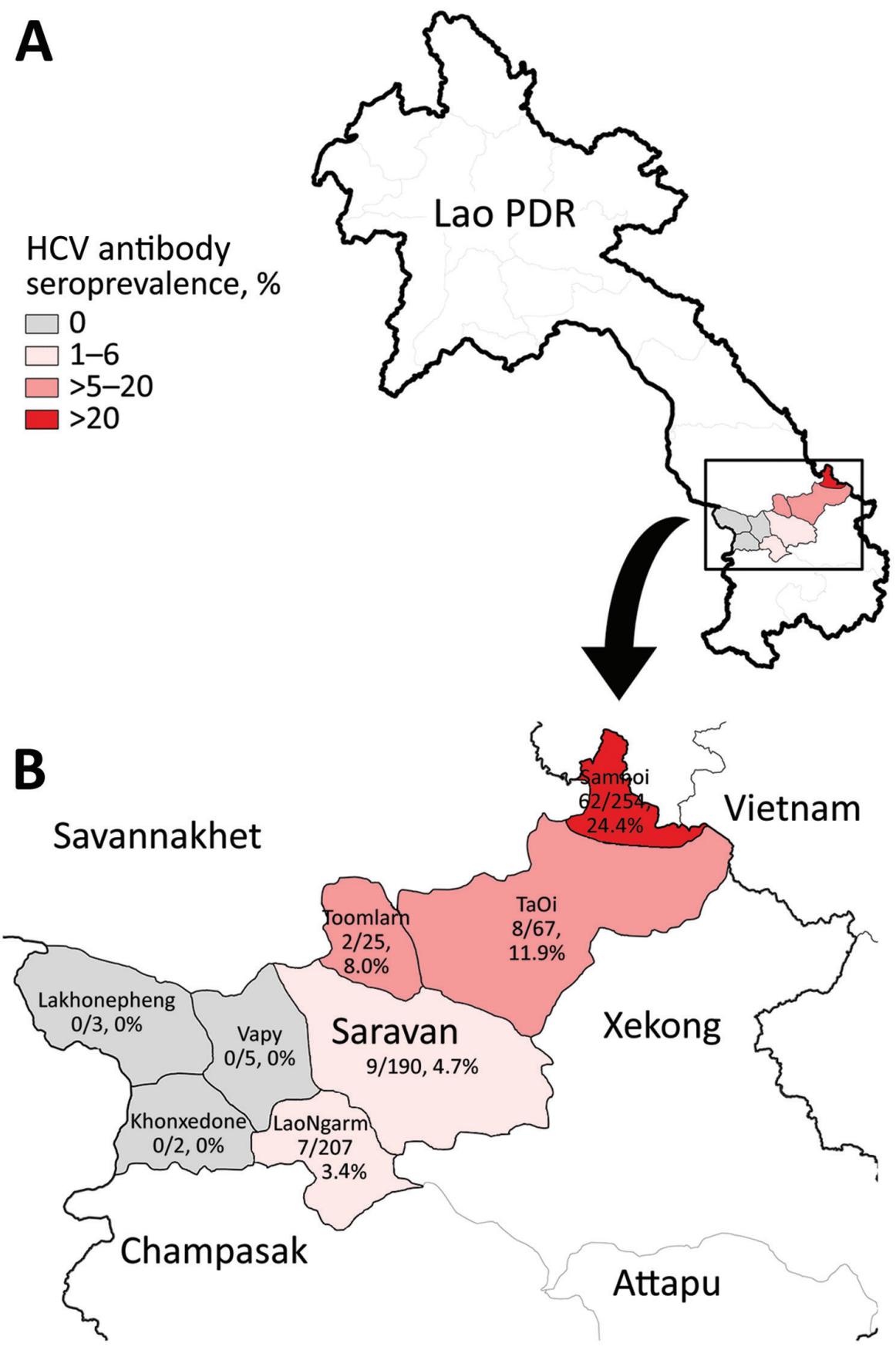

HCV antibody seroprevalence, \%

B 
Table. Bivariate and multivariate analysis of HCV antibody positive cases, Laos, May 2017-March 2019*

\begin{tabular}{|c|c|c|c|c|c|}
\hline \multirow[b]{2}{*}{ Variable } & \multirow[b]{2}{*}{ Positive no./total no. (\%) } & \multicolumn{2}{|c|}{ Bivariate } & \multicolumn{2}{|c|}{ Multivariate } \\
\hline & & OR $(95 \% \mathrm{Cl})$ & $p$ value & OR $(95 \% \mathrm{Cl})$ & $\mathrm{p}$ value \\
\hline \multicolumn{6}{|l|}{ Sex } \\
\hline $\mathrm{F}$ & $42 / 417(10.1)$ & Referent & NA & Referent & NA \\
\hline $\mathrm{M}$ & 46/336 (13.7) & $1.4(0.9-2.2)$ & 0.126 & $1.5(0.9-2.6)$ & 0.08 \\
\hline \multicolumn{6}{|l|}{ Age group, $y$} \\
\hline$\leq 30$ & $18 / 403(4.5)$ & Referent & & Referent & NA \\
\hline$>30$ & $70 / 350(20)$ & $5.3(3.1-9.2)$ & $<0.001$ & $4.2(2.1-8.5)$ & $<0.001$ \\
\hline \multicolumn{6}{|l|}{ District† } \\
\hline Lao Ngarm & $7 / 207(3.4)$ & Referent & & NA & NA \\
\hline Saravan & 9/190 (4.7) & $1.4(0.5-3.9)$ & 0.495 & NA & NA \\
\hline Samuoił & $62 / 254(24.4)$ & $9.2(4.1-20.7)$ & $<0.001$ & NS & NS \\
\hline $\mathrm{Ta} \mathrm{Oi}$ & $8 / 67(11.9)$ & $3.9(1.3-11.1)$ & 0.012 & NS & NS \\
\hline Toomlarn & $2 / 25(8)$ & $2.5(0.5-12.7)$ & 0.274 & NA & NA \\
\hline Vapy & $0 / 5(0)$ & NA & NA & NA & NA \\
\hline Khongxedone & $0 / 2(0)$ & NA & NA & NA & NA \\
\hline Lakhonepheng & $0 / 3(0)$ & NA & NA & NA & NA \\
\hline \multicolumn{6}{|l|}{ Marital status } \\
\hline Single & $7 / 268$ (2.6) & Referent & NA & Referent & NA \\
\hline Married or other & $81 / 485$ (16.7) & $7.5(3.4-16.4)$ & $<0.001$ & $2.7(1.0-7.3)$ & 0.04 \\
\hline \multicolumn{6}{|l|}{ Occupation } \\
\hline Student or other & $7 / 231(3)$ & Referent & NA & NA & NA \\
\hline Employee & $14 / 67$ (20.9) & $8.5(3.3-21.9)$ & $<0.001$ & NS & NS \\
\hline Farmer & $67 / 455(14.7)$ & $5.5(2.5-12.2)$ & $<0.001$ & NS & NS \\
\hline \multicolumn{6}{|l|}{ Ethnicity } \\
\hline Non-Pako & $22 / 488(4.5)$ & Referent & NA & Referent & NA \\
\hline Pako & $66 / 265(24.9)$ & $7(4.2-11.7)$ & $<0.001$ & $5.1(2.7-9.7)$ & $<0.001$ \\
\hline \multicolumn{6}{|l|}{ Religion } \\
\hline Buddhist or other & $7 / 258(2.7)$ & Referent & NA & Referent & NA \\
\hline Animism & $81 / 495(16.4)$ & $7(3.2-15.4)$ & $<0.001$ & $3(1.2-7.6)$ & 0.02 \\
\hline \multicolumn{6}{|l|}{ Place of birth } \\
\hline At hospital or unknown & $57 / 440(12.9)$ & Referent & NA & NA & NA \\
\hline At home & $31 / 313(9.9)$ & $0.7(0.4-1.2)$ & 0.2 & NA & NA \\
\hline \multicolumn{6}{|l|}{ Diagnosis } \\
\hline Hepatitis non-related or unknown & $86 / 702(12.3)$ & Referent & NA & Referent & NA \\
\hline Related to hepatitis & $2 / 51(3.9)$ & $0.2(0.1-1.2)$ & 0.09 & $0.2(0.1-1.1)$ & 0.07 \\
\hline
\end{tabular}

were obtained, and the many genetically diverse clusters even in the same district (Samuoi) might indicate different infection sources. However, we cannot rule out a more distant large-scale transmission event. The new strains added to the genetic diversity of genotype 6 viruses found in a previous study from central and northern Laos provinces (5); this increased diversity has potential consequences for the use of commercial assays (9) and treatment strategies (10).

The high rates of death and illness associated with chronic HCV infection suggest that a large proportion of the Saravan population will experience liver-related complications in the future. Despite a reduction in costs of direct-acting antiviral drugs, access to testing and treatment remains low in Laos. An in-depth casecontrol study to determine sources of infection and associated risk factors is warranted. Furthermore, evaluations of infection prevention, screening, and control measures in healthcare facilities and blood banks, as well as the general population, are needed.

\section{Acknowledgments}

We thank the participants for agreeing to take part in this study; Latdavone Khenkha, Bounta Vongphachanh, and Nouna Innoula for technical assistance in the laboratory; and Lisa Hefele for advising on the statistical analysis. We also thank Paul Brey and the administration of the Institut Pasteur du Laos for continued support and all staff at the provincial and district hospitals.

The work was supported by the Luxembourg Ministry of Foreign and European Affairs and the Luxembourg Institute of Health (PaReCIDS II grant), and the authors have full control over all primary data.

\section{About the Author}

Dr. Black is the head of a research laboratory in the Institut Pasteur du Laos, Vientiane, Laos. His current research focuses on the immunology and public health burden of vaccine-preventable infectious diseases in Lao PDR. 


\section{References}

1. Bellentani S, Tiribelli C. The spectrum of liver disease in the general population: lesson from the Dionysos study. J Hepatol. 2001;35:531-7. https:/ / doi.org/10.1016/ S0168-8278(01)00151-9

2. Lao Statistics Bureau and UNICEF. Lao social indicator survey II, 2017, survey findings report. 2018 [cited 2021 Nov 2]. https:/ / www.unicef.org/laos/media/306/file/ LSIS2017ENG.pdf

3. Xaydalasouk K, Sayasinh K, Hübschen JM, Khounvisith V, Keomany S, Muller CP, et al. Age-stratified seroprevalence of vaccine-preventable infectious disease in Saravan, Southern Lao People's Democratic Republic. Int J Infect Dis. 2021;107:25-30. https:// doi.org/10.1016/j.ijid.2021.04.033

4. Black AP, Vilivong K, Nouanthong P, Souvannaso C, Hübschen JM, Muller CP. Serosurveillance of vaccine preventable diseases and hepatitis $C$ in healthcare workers from Lao PDR. PLoS One. 2015;10:e0123647. https:/ / doi.org/10.1371/journal.pone.0123647

5. Hübschen JM, Jutavijittum P, Thammavong T, Samountry B, Yousukh A, Toriyama $\mathrm{K}$, et al. High genetic diversity including potential new subtypes of hepatitis $C$ virus genotype 6 in Lao People's Democratic Republic. Clin Microbiol Infect. 2011;17:E30-4. https:/ / doi.org/10.1111/ j.1469-0691.2011.03665.x

6. Viet L, Lan NTN, Ty PX, Björkvoll B, Hoel H, Gutteberg T, et al. Prevalence of hepatitis B \& hepatitis $C$ virus infections in potential blood donors in rural Vietnam. Indian J Med Res. 2012;136:74-81.

7. Riondel A, Huong DT, Michel L, Peries M, Oanh KTH, Khue PM, et al. Towards targeted interventions in lowand middle-income countries: risk profiles of people who inject drugs in Haiphong (Vietnam). BioMed Res Int. 2020;2020:8037193. https:// doi.org/10.1155/2020/8037193

8. Schmutz J. The Ta'Oi language and people. Mon-Khmer Stud. 2013;42:i-xiii.

9. Mallory MA, Lucic DX, Sears MT, Cloherty GA, Hillyard DR. Evaluation of the Abbott realtime HCV genotype II RUO (GT II) assay with reference to 5'UTR, core and NS5B sequencing [Erratum in: J Clin Virol. 2014;61:625]. J Clin Virol. 2014;60:22-6. https:/ / doi.org/10.1016/j.jcv.2014.02.006

10. Shin SR, Kim YS, Lim YS, Lee JS, Lee JW, Kim SM, et al. Clinical characteristics and treatment outcome of peginterferon plus ribavirin in patients infected with genotype 6 hepatitis $C$ virus in Korea: a multicenter study. Gut Liver. 2017;11:270-5. https://doi.org/10.5009/ gnl16163

Address for correspondence: Antony P. Black, VaccinePreventable Disease Laboratory, Institut Pasteur du Laos, Rue Samsenthai, Ban Kao-gnot, Vientiane, Laos; email: a.black@pasteur.la

\section{Limited Propagation of SARS-CoV-2 among Children in a Childcare Center, Canada, 2021}

\author{
Anthony Li, Kieran Moore, Lindsay Bowthorpe, \\ Julie Sousa, T. Hugh Guan \\ Author affiliations: Kingston, Frontenac, Lennox \& Addington \\ Public Health, Kingston, Ontario, Canada (A. Li, K. Moore, \\ L. Bowthorpe, J. Sousa, T.H. Guan); Queen's University, Kingston \\ (A. Li, K. Moore, L. Bowthorpe, T.H. Guan); Ministry of Health of \\ Ontario, Toronto, Ontario, Canada (K. Moore)
}

DOI: https://doi.org/10.3201/eid2801.211811

An outbreak of severe acute respiratory syndrome coronavirus 2 with no definitive source and potential exposure to variants of concern was declared at a childcare center in Ontario, Canada, in March 2021. We developed a robust outbreak management approach to detect, contain, and interrupt this outbreak and limit propagation among children.

$\mathrm{O}$ March 1, 2021, an infant enrolled at a childcare center in the Kingston, Frontenac, Lennox, and Addington region in Ontario, Canada tested positive for severe acute respiratory syndrome coronavirus 2 (SARS-CoV-2); however, no acquisition source was identified. The next day, another 7 children and staff at the facility tested positive, and an outbreak was declared.

We immediately searched for potential transmission events and deployed a public health inspector and nurse team. The infant had last attended the childcare center $>3$ days before symptom onset, beyond the 48-hour window for exposure risk according to standard guidance (1). Furthermore, the assessment team identified no travel, occupational, or other contact risks. Out of an abundance of caution, we extended the period of communicability (POC) from 48 to 96 hours, which defined the childcare center as an outbreak setting. We identified staff who had recently traveled to regions with high proportions of SARS-CoV-2 variants of concern (VOC). We were concerned that the increased transmissibility and virulence of a potential VOC outbreak in a childcare center could rapidly spread through the community, given recent studies demonstrating SARS-CoV-2 infection and transmission among children $(2,3)$.

Case investigators gathered symptom profiles, onset dates, detailed exposure histories, risk 